\title{
VPS - The Virtual Police Station 24*7 with Aadhar card Authentication
}

\author{
Sanjukta Banerjee ${ }^{[1]}$ Rohini Bale $^{[2]}$ Diksha Vazirani ${ }^{[3]}$ Tanushree Shrivas $^{[4]}$ Saloni Fating ${ }^{[5]}$ \\ Student, Department of Information Technology, S.B. Jain Institute of Technology, Management and Research,

$$
\text { Nagpur, India }{ }^{1-5}
$$

\begin{abstract}
The idea of virtual policing and also the specificity of however it's completely different has not even been remotely explored thus far. there's a kind of a probe for a path to traverse however police may establish AN entry into the assorted virtual communities. once we go searching the international scene, we discover an equivalent issue, there area unit innovative practices and hesitant makes an attempt that area unit sometimes contradicting themselves. this text could be a reasonably a situational exposure, an summary of what the police profession is thinking, what initiatives area unit being taken advantage of by the assorted authorities worldwide.
\end{abstract}

Keywords: Virtual station, 1st info Report(FIR), Adharcard, AWS, Realtime

\section{I.INTRODUCTION}

Police Station Management System is predicated on the conception of managing criminal records. Before going in the most menu a user has got to go through a login system to induce access, then the user will manage criminal records by adding, updating, removing, viewing and looking for details. This mini project contains restricted options, however the essential one.

Talking regarding the options of the station management system, the user will add numerous info of the criminals. For that, the user has got to offer convict's id, name, age, gender, height, weight, crime, face details, conviction etc. with the exception of this, the user will view/check a listing of the records, search, modify and take away records too. The user simply has got to offer convict id so as to go looking for a criminal's record.

The police management system is Associate in Nursing application that enables all the paper work that square measure drained the station to be keep in one single system with nice ease. It will facilitate in handling the records easier. generally if there's a necessity for a few info of a specific criminal then you would like to go looking in Brobdingnagian heap of files wherever that info is keep in those files. in order that can involve in wastage of your time and conjointly effort. therefore to beat these issues, the police management system is helpful. this may scale back loads of pen paper work that's concerned.

\section{Objectives:}

- To scale back excessive paper work on station.

- To save time of police and other people.

- $\quad$ To build the method of filing Associate in Nursing FIR additional convenient for each police and customary folks.

\section{II.LITERATURE SURVEY}

\section{Askthe.police.uk:}

This is a platform already designed by Britain police to file fir just about. The Virtual station (VPS) serves twin functions as Associate in Nursing innovative coaching tool for cops and an academic tool for the general public. Users square measure able to expertise and explore each area among a station in 360 degrees.[1]

The VPS provides video, text, and legal resources in multiple layers to facilitate coaching in multiple languages. This interactive instructional coaching tool is totally integrated into social media and has the flexibility to be operated each on and offline. it's been delineate by senior police officers as a useful resource and ground breaking platform for police academies, NGOs operating to empower communities, and public education on policing procedures and rights.

2. Indian Virtual police stations:

The Commonwealth Human Rights offers the Virtual station website and therefore the material contained in that as a free resource to someone user or educational establishment subject to the subsequent terms and conditions: 


\section{International Advanced Research Journal in Science, Engineering and Technology}

Vol. 8, Issue 5, May 2021

DOI: $10.17148 /$ IARJSET.2021.8579

-Use are going to be for non-commercial functions.

- Use is among correct attribution to the CHRI and therefore the author(s) because the supply of any info contained in a very publication or multimedia system resource.

-Unauthorized repeating or manipulation of content is expressly prohibited.

-Nothing on the web site constitutes, or is supposed to represent, recommendation of any kind. If you need recommendation in respect to any legal, monetary or medical matter you ought to consult Associate in Nursing applicable skilled.

-The terms of use are going to be ruled by and construed in accordance with the laws of Republic of India, and any disputes with reference to these terms and conditions are going to be subject to the exclusive jurisdiction of the courts of Republic of India.

By accessing our service you're indicating your agreement that you just won't use the Virtual station website in dispute of the higher than conditions. CHRI reserves the proper to discontinue this service at any time and additional reserves the proper to request the immediate surcease of any specific use of its service. we have a tendency to hope you get pleasure from this service from CHRI.[2]

\section{III.PROPOSED WORK}

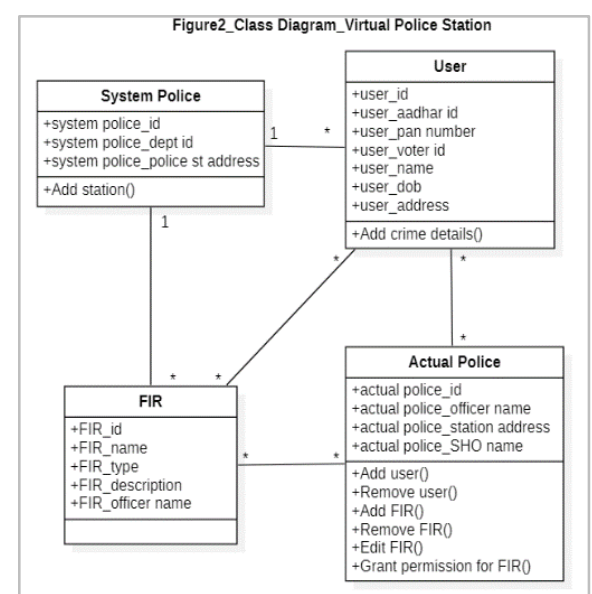

Fig.1.System Class Diagram

The intent of our project is that the users ought to be able to file Associate in Nursing FIR just about anytime. the most intention is to cut back the manual work of cops and to allow a platform to the victim to stay track on the FIR they filed. To convert the FIR into the right format of FIR utilized by the officers and to verify the user with the Adhar Card authentication. If the Adhar card authentication is unsuccessful, then the user can airt to login page directly. once filing the FIR and supportive the victim the admin will access the FIR and might modify or delete the FIR in step with the registered case.

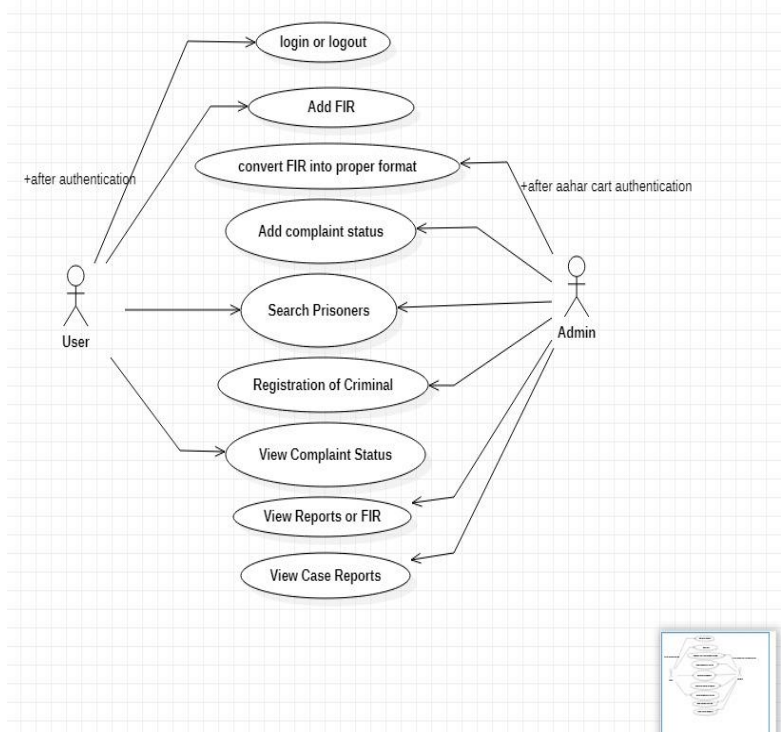

Fig.2.System Use Case Diagram 


\section{International Advanced Research Journal in Science, Engineering and Technology}

Vol. 8, Issue 5, May 2021

DOI: $10.17148 /$ IARJSET.2021.8579

\section{Modules:}

1) Creating a info in order that admin will access the FIR and might delete or modify it.

2) Developing the appliance victimization AWS Associate in Nursing providing an interface to the user therefore he/she will file and FIR directly.

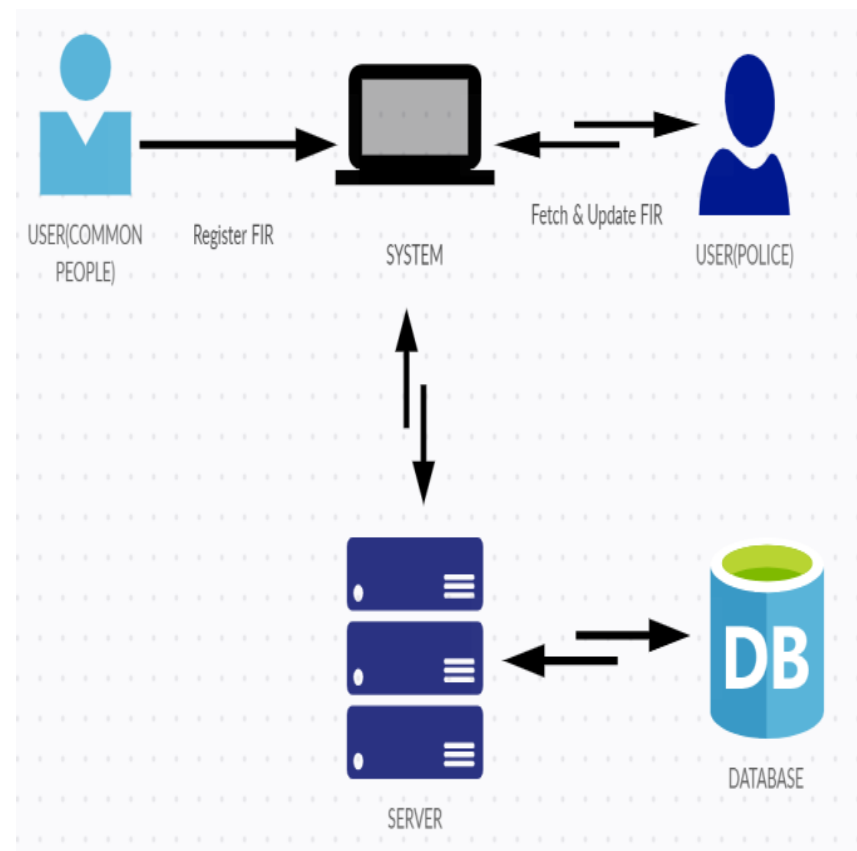

Fig.3.System Architecture Diagram

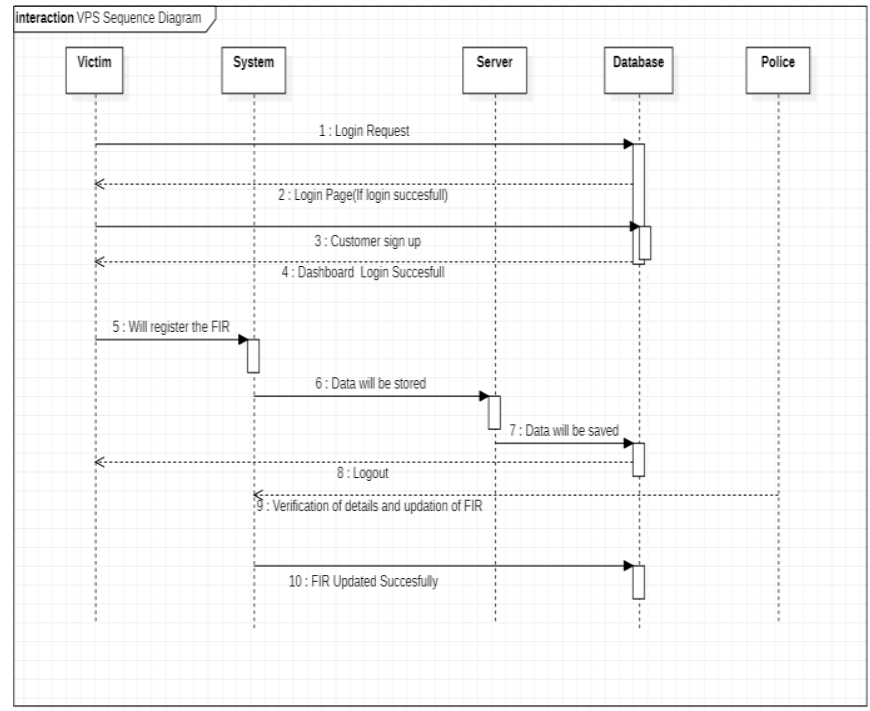

Fig.4.System Sequence Diagram

\section{User module}

1) The user can register to the app, whereas registering the authentication are going to be performed from the admin aspect. once authentication the user can airt to the interface wherever he/she can see a virtual police man asking a listing of question associated with the grievance.

2) After respondent the question, the FIR can convert into the formal format of FIR.

3) The user can then transfer their Adhar card manually, if the Adhar card is verified then the FIR can send to the admin and if not then user can airt to the primary page.

4) The user will read or delete their FIR and see what actions has been taken to that. 


\section{International Advanced Research Journal in Science, Engineering and Technology}

Vol. 8, Issue 5, May 2021

DOI: $10.17148 /$ IARJSET.2021.8579

\section{Admin module}

1) Admin will management the info and might print the FIR .

2) If the admin feels that the FIR is fake or the difficulty that is register is fake, the they will delete the FIR and therefore the user the desire be told that the FIR is been deleted by the admin.

3) The admin will modify the FIR in step with the norms they follow.

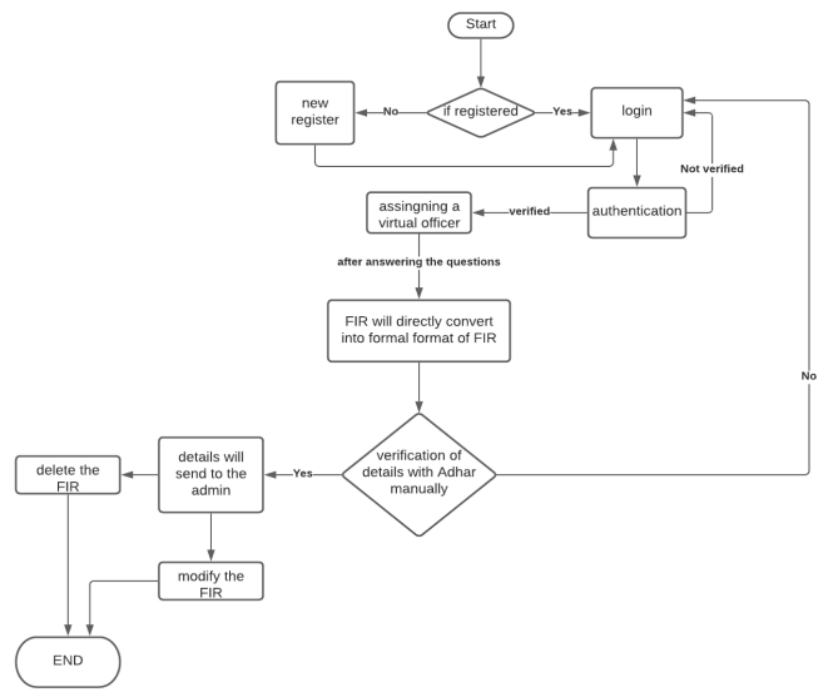

Fig.5.System Flowchart Diagram

\section{CONCLUSIONS}

We have designed a web based application for filing an FIR which acts as interface between police \& common people. The application is available for everyone who is accessible to internet and a device to run the software on. We have applied engineering knowledge to analyze societal problem of common people to file an FIR \& then designed solution for it. We have analyzed existing websites \& mobile apps related to filing FIRs \& tried to overcome their drawbacks in our project. We have used modern tool such as VS Code and AWS to implement the project. During this project we have applied professional ethics \& understand importance of teamwork \& project presentation in various competitions $\&$ conferences for project management, which leads to engage our self in lifelong learning.

\section{REFERENCES}

\footnotetext{
Paper International Journal of Innovative Research in Science, Engineering and Technology (Vol. 5, Issue 10, October2016) Applications (0975 - 8887) (Volume 5- No.5, August2010) tracking", Proceedings of the 2nd International Conference on Intelligent Information Processing, Article No.32,2017-07-17

\section{Website}

[1] https://medium.com/inborn-experience/top-10-ar-furniture-apps-review-in-2017-c75c8f20775e

[2] https://learn.homestyler.com/sad-that-neybers-shut-down-homestyler-is-here-for-you/

[3] https://www.crunchbase.com/organization/neybersinfectious disease journal, 15(7):600-604, 1996
}

[1] Kalyani Pampattiwar, Akshay Adiyodi, Manasvini Agrahara, Pankaj Gamnani, "Interior Design using Augmented Reality Environment",

[2] Viet Toan Phan, Seung Yeon Choo, "Interior Design in Augmented Reality Environment", International Journal of Computer

[3] Waraporn Viyanon, “AR Furniture: Integrating Augmented Reality Technology to Enhance Interior Design using Marker and Marker less 